\title{
Impact, Perception, Role and Expectations of Sleep Partners of Patients Suffering from Sleep Apnea Syndrome and Treated at Home by CPAP: Results of a Large Scale Study of More than 900 Patients
}

\author{
Eytan Ellenberg*,1, Alfandary Didier ${ }^{2}$, Dehecq Bertrand ${ }^{1}$, Crone Véronique ${ }^{1}$, Izarn Laurence ${ }^{1}$, \\ Martinez Philippe ${ }^{1}$, Chambouleyron Monique ${ }^{3}$ and Racineux Jean-Louis ${ }^{4}$ \\ ${ }^{\prime}$ Medical Direction, Orkyn' (Air Liquide), Gentilly, France \\ ${ }^{2}$ Pneumology, Corbeil-Essonnes Polyclinic, France \\ ${ }^{3}$ SETMC, Geneva University Hospital, "Association Passerelles Éducatives" (Educational Bridges Association). \\ Switzerland \\ ${ }^{4}$ Pneumology, Angers University Hospital, "Association Passerelles Éducatives" (Educational Bridges Association), \\ France
}

\begin{abstract}
Objective: Sleep apnea is a breathing disorder requiring treatment by CPAP. The impact of sleep apnea and how the condition and its treatment are perceived by partners have been studied in small populations. However, few large scale studies have focused on the role and expectations of partners of patients treated with CPAP.

Methods: descriptive study of responses to questionnaires sent to 2,059 patients treated for Sleep apnea by CPAP for 6 months and to their partners.

Results: 922 questionnaires returned by patients, 673 by partners. 37\% sought medical help for the first time upon the partner's initiative. Male patients evoke the breathing pauses occurring at night reported by their partner and a decrease in sexual activity. Female patients focus more on the quality of sleep, tiredness and signs relating to depression. Male patients were more often accompanied by their sleep partner than female patients. For $80 \%$ of patients, the partner had a positive effect on initiation of the treatment. Sleep partners talk openly with the patients about the treatment (93\%) and encourage them to continue with it $(93 \%)$. For sleep partners, the benefits of treatment are essentially felt with respect to the quality of sleep. Overall, the benefits of the treatment outweigh the constraints.

Conclusions: Sleep apnea and CPAP undoubtedly have an effect on partners. The latter play an important role in the initiation and continuation of the treatment.

Practice Implications: Patients and partners have specific expectations which must be taken into account by doctors and Home Care Providers.
\end{abstract}

Keywords: Sleep apnea syndrome, CPAP, partners, impact, role, expectations, Home Care Providers, specialists.

\section{INTRODUCTION}

Sleep Apnea Syndrome is a disorder characterized by recurrent nocturnal episodes of apnea and hyperpnoea leading to desaturation and micro-arousal. A strong correlation has been established between SLEEP APNOEA SYNDROME and the risk to health (notably cardiovascular risk, risk of road accidents following sudden sleepiness, etc.) [1]. In France, patients suffering from this type of sleep-related breathing disorder are managed by the lung specialist.

These patients, who are often snorers, also suffer from day-time sleepiness, morning headaches and tiredness, but may also present with more obvious signs and it is often the sleep partner, alerted by the excessively loud and heavy snoring and/or periods of breathing cessation during sleep, who seeks medical advice first.

*Address correspondence to this author at the Medical Direction, Orkyn' (Air Liquide), Gentilly, 28rue d'Arcueil 94257 Gentilly Cedex, France;

E-mail: Eytan.ellenberg@orkyn.fr
It is believed that SLEEP APNOEA SYNDROME affects almost $2 \%$ of women and $4 \%$ of men [2]. As SLEEP APNOEA SYNDROME is related to obesity and to metabolic syndrome, and given the epidemiological increase in this type of disorder, it is clear that more and more patients will be affected by SLEEP APNOEA SYNDROME in the years to come [3] and [4]. The preferred treatment for SLEEP APNOEA SYNDROME today is home ventilation by means of a Continuous Positive Airway Pressure (CPAP) device, which is only effective if used for 4 to 5 hours per day.

Within this context, studies have effectively demonstrated the impact of the disease and treatment on the quality of life of patients and their sleep partners [5] and [6]. Parish and Lyng [7] studied the effect of the disease and of CPAP treatment on 54 patients and their sleep partners. They found that while the disease had a clearly negative impact on the quality of life of patients and their partners, CPAP treatment had a rather positive effect. Other studies have also analyzed 
the effect of the disease on the sleep partner [6] with regard to sleep disturbance [8] and quality of life [9-11].

Few studies, however, have focused on the perception, expectations and above all the role played throughout treatment by those close to patients with SLEEP APNOEA SYNDROME and treated by CPAP, on a large number of patients. The objectives of this large scale study of more than 900 patients and sleep partners are to describe the differences in perception between patients and their partners, to more effectively analyze expectations and to clearly define the role played by sleep partners in the acceptance of the disease and its treatment. The scope of the study will make it possible to describe more specifically the role played by the family circle in caring for SLEEP APNOEA SYNDROME sufferers.

\section{MATERIALS AND METHODS}

The study was carried out on patients suffering from SLEEP APNOEA SYNDROME who had been fitted with a CPAP device more than 6 months previously. All patients underwent respiratory polygraphy (and polysomnography if doubt persisted) to establish the diagnosis (Index of apnea/hypopnea $>30 / \mathrm{h}$ ) and, after a pressure titration phase with an AutoSet machine and therapeutic education, were regularly monitored by their specialist ( 5 months after the CPAP device was fitted then every year) and by a technician from the Home Care Provider service (within the first month after fitting, four months later, then every six months). The patients were monitored by various sleep centers (community or hospital-based). 2,059 questionnaires were sent by post in the summer of 2006 to patients and to their partners where appropriate (a copy of the questionnaire is presented in the annexes). This was a multiple choice questionnaire. A crossover statistical analysis and a Chi2 significance test were performed on the completed questionnaires.

\section{RESULTS}

922 questionnaires were returned by patients and 673 by their partners.

\subsection{Patient Profile (Table 1)}

The patient profile is based on answers from the questionnaire only.

Patients suffering from SLEEP APNOEA SYNDROME and treated by CPAP are, for the main part, retired $(64 \%)$, male $(76 \%)$ and of an average age of 64 years (only $11 \%$ of patients are under 50). Sleep partners are mainly female (79\%), of an average age of 61 years and mainly retired (see Table 1).

$81 \%$ do not live alone, $97 \%$ have a sleep partner and $29 \%$ have children living at home. $19 \%$ of patients live alone and have done so for 13 years on average; a situation which, according to the patients, is not necessarily related to their condition or its treatment (this only applies to $11 \%$ of patients). Women were found to live alone more frequently than men (Women: $35 \%$ vs. Men: $14 \%, \mathrm{p}<0.001$ ). The patients had been receiving CPAP treatment for 3 or 4 years on average (3/4 have had the device for more than a year).

\subsection{Origin and Initiation of Treatment}

Before treatment was started, only $1 / 3$ of patients were aware that they had SLEEP APNOEA SYNDROME and

Table 1. Population of Patients and Sleep Partners

\begin{tabular}{|c|c|}
\hline Feature & Value \\
\hline Male & $76 \%$ \\
\hline Female & $24 \%$ \\
\hline Age & 64 years on average (sleep partners 61 years) \\
\hline Smoker & $12 \%$ (sleep partner $11 \%$ ) \\
\hline With a sleep partner or other partner & $81 \%$ (97\% sleep partner with $29 \%$ children at home) \\
\hline Alone & $19 \%$ \\
\hline Length of treatment & 3.4 years (average) \\
\hline Less than a year & $23 \%$ \\
\hline \multicolumn{2}{|l|}{ Socioprofessional activity } \\
\hline Retired & $64 \%$ (sleep partners $55 \%$ ) \\
\hline Non-executive managers & $9 \%$ (sleep partners $15 \%$ ) \\
\hline Executive managers & $9 \%$ (sleep partners $5 \%$ ) \\
\hline Worker & $5 \%($ sleep partners $3 \%)$ \\
\hline Unemployed & $4 \%$ (sleep partners $12 \%$ ) \\
\hline Others & $10 \%$ (sleep partners $10 \%$ ) \\
\hline
\end{tabular}




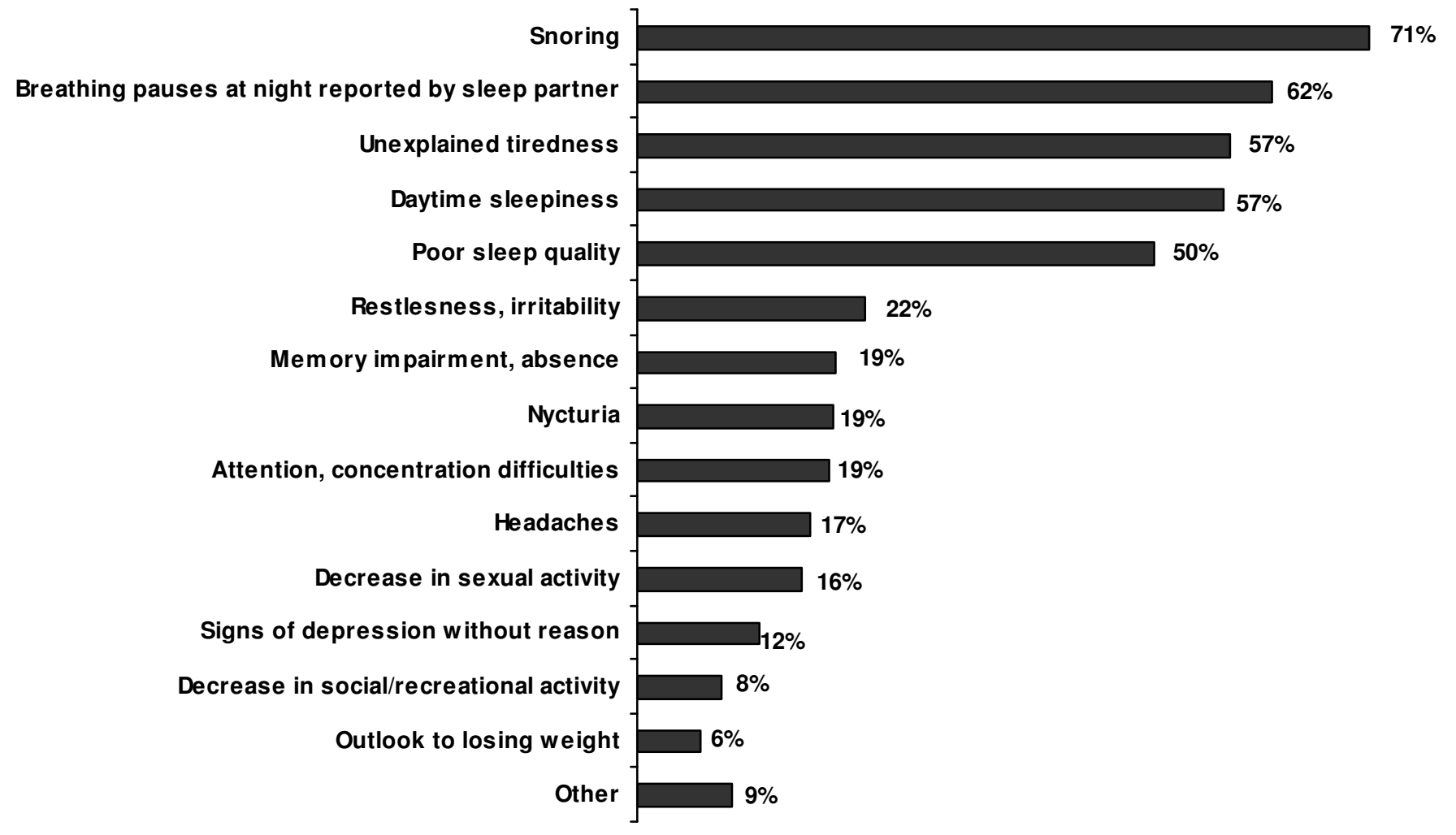

Fig. (1). Patients' symptoms leading to consultation.

only $17 \%$ had heard about CPAP treatment. Professional medical advice is often sought for the first time following referral by the general practitioner but the sleep partner also played an important role (instigator in $37 \%$ of cases), especially with respect to male patients $(41 \%)$. Only $21 \%$ of patients sought medical advice on their own initiative.

The symptoms having prompted consultation with a doctor were essentially related to sleep and tiredness: on average, patients sought medical advice because of 4 to 5 symptoms (Fig. 1). Slight differences arise depending on sex: men mainly describe nocturnal breathing pauses (most frequently reported by their sleep partner) and a decrease in sexual activity, whereas women are more sensitive to the quality of sleep, to tiredness and to signs related to depression $(\mathrm{p}<0.005)$.

For $74 \%$ of patients, the family circle's reaction to sleep recording at home was positive. Almost half of patients' sleep partners were not present when the diagnosis was announced. A higher proportion of women attended their appointment alone (Women: $42 \%$ vs. $55 \%$. p < 0.003 ).

Information relating to SLEEP APNOEA SYNDROME and CPAP was provided essentially by the medical profession. Both the patients and their sleep partners obtained additional information from their general practitioner (more than $70 \%$ ). Internet sites are used by $9 \%$ of patients, although this percentage is slightly higher amongst younger subjects (15\%). For $80 \%$ of patients, partners were seen to have a positive influence on CPAP use.

\subsection{Treatment Monitoring}

$61 \%$ of patients felt their general practitioner played a positive role in treatment monitoring (vs. 3\% negative), but that the role played by family members was more significant.
The treatment provided relief for $44 \%$ of patients, with $72 \%$ reporting a feeling of well-being, "I'm fine", and $40 \%$ getting more out of life. Patients reported an improvement in quality of life resulting from a more positive "psychological state":

- feeling worn out: $29 \%$ decrease

- restlessness: $22 \%$ decrease

- anxiety: $18 \%$ decrease

- depression: $14 \%$ decrease

and also evoked a rise in both social and marital satisfaction.

The benefits of treatment are essentially felt as regards the quality of the patient's sleep, but also that of the sleep partner. The positive effects on the family, in the home and at work are less marked. $91 \%$ of patients find that they have a good quality of life (96\% for sleep partners).

CPAP is considered to be reliable, easy to maintain and handle, but is criticized for its unsightly appearance and noise level. Overall, the benefits of the treatment outweigh the constraints for $87 \%$ of patients and $94 \%$ of sleep partners.

Sleep partners talk openly with the patient about treatment $(93 \%)$ and encourage the patient to continue $(93 \%)$. They also help the patient to maintain appropriate dietary habits $(75 \%)$. Anxiety, discomfort and constraints relating to the disorder / treatment are the most sensitive subjects for couples (almost 50\% do not talk about them). Men are more effectively supported by their partner than women.

Both patients and sleep partners expect to receive comprehensive information concerning the disease and its treatment (duration, adjustments and side effects) and to a lesser 
Table 2. What Patient Felt Hey Need with Respect to the Doctor and the Home Care Provider

\begin{tabular}{|c|c|c|c|c|}
\hline & Patient & Partner & Patient & Partner \\
\hline Detailed explanations concerning the disease & $35 \%$ & $40 \%$ & $15 \%$ & $16 \%$ \\
\hline More information on mask CPAP & $19 \%$ & $16 \%$ & $53 \%$ & $46 \%$ \\
\hline More information concerning the benefits of the treatment (on driving for example) & $24 \%$ & $24 \%$ & $21 \%$ & $20 \%$ \\
\hline More information on treatment adjustment & $43 \%$ & $57 \%$ & $35 \%$ & $40 \%$ \\
\hline Assistance with respect to dietary habits & $33 \%$ & $32 \%$ & $13 \%$ & $13 \%$ \\
\hline Contact with other patients or associations & $5 \%$ & $5 \%$ & $7 \%$ & $7 \%$ \\
\hline More personnalised care taking into account my difficulties and my way of life & $11 \%$ & $9 \%$ & $12 \%$ & $7 \%$ \\
\hline Improved communication and more information for my family doctor & $17 \%$ & $20 \%$ & $13 \%$ & $12 \%$ \\
\hline More information concerning the possible side effects and treatment & $36 \%$ & $36 \%$ & $38 \%$ & $42 \%$ \\
\hline More information concenring the lifestyle changes to be made (diet, exercise) & $24 \%$ & $22 \%$ & $15 \%$ & $15 \%$ \\
\hline Increased transparency as to length of treatment & $48 \%$ & $43 \%$ & $29 \%$ & $32 \%$ \\
\hline $\begin{array}{l}\text { Increased involvement of my partner at the time of diagnosis and/or upon implementation of the treat- } \\
\text { ment }\end{array}$ & $5 \%$ & $12 \%$ & $5 \%$ & $10 \%$ \\
\hline Others & $2 \%$ & $3 \%$ & $6 \%$ & $3 \%$ \\
\hline
\end{tabular}

extent concerning dietary habits (see Table 2). Expectations with respect to the Home Care Provider are different: patients expect to receive information concerning the CPAP device and masks. Patients also expect to receive information concerning the treatment (duration, adjustments and side effects (see Table 2)).

\section{DISCUSSION}

This large scale study, the first of its type in terms of the number of patients and sleep partners questioned, highlights the importance of the role of the patient's family circle both in detecting and diagnosing SLEEP APNOEA SYNDROME through observation, but also in the acceptance, monitoring and help in evaluating the efficacy of CPAP for patients suffering from SLEEP APNOEA SYNDROME. The relevance of "Global Disease Management" and of therapeutic education for patients has increased over the last few years. Can the patient still be associated with his family circle where his health is concerned and where disease management may prove to be complex? Despite methodological bias, several elements emerge concerning the role played by the sleep partner in the management of the disease and underline the need for their closer involvement in caring for patients.

\section{At Diagnosis and Upon Treatment Initiation}

The majority of patients are male, aged over 60 years old, are retired and mostly live with a partner (with or without children); this type of device inevitably therefore has an effect on the relationship. In an altogether surprising manner, however, the sleep partner appears to exert a strong influence with respect to acceptance of the disease (i.e. in recognizing that the specific symptoms, which may appear to be insignificant, represent a serious medical concern) and its treatment by the patient. A significant proportion of patients (more than one third) sought medical advice at the request of the partner. This is notably the case of the many patients for whom the symptoms are sleep-related (snoring and nocturnal apnea) and which are not noticed by the patients themselves. Male patients tend to rely more on their sleep partner when managing the disease and half of them attended their appointment with this partner. Patients also refer to the positive role played by their family circle during the diagnostic tests. The family circle's contribution to the care of patients suffering from SLEEP APNOEA SYNDROME, especially at the start but also during CPAP treatment, appears to be essential in daily practice.

The different male/female perceptions of the disease and of the treatment must be taken into account if it is to be managed as effectively as possible. Men tend to focus on the breathing pauses at night as described by their sleep partner and on decreased in sexual activity; women are more sensitive to quality of sleep, tiredness and signs related to depression. These different perceptions should be interpreted by the doctor and the Home Care Provider in such a way so as to effectively manage care, which in the long run, can sometimes prove to be complex. Patients tended to describe 4 to 5 different symptoms during the appointment. 


\section{On Starting and Pursuing Treatment}

Patients clearly state that their general practitioner played a positive role even if his/her influence was less positive than that of the family circle. In actual fact, allowing the sleep partner to talk more freely about the effects of the disorder, and above all of the CPAP device, on the couple must seen as a way of dealing with certain issues. Despite the impact of this type of treatment on the relationship, the sleep partner is known to play an essential role - especially when the patient continues to use the device. Finally the expectations of patients and sleep partners differ with respect to the specialist and the Home Care Provider, which stresses the importance of access to a variety of sources of information. Patients fitted with CPAP devices and who are globally satisfied with the treatment and level of care they receive have as yet unmet needs as regards the information and patient education received from their doctor.

This study obviously shows methodological weaknesses. First of all, there is nothing to guarantee that all of the questionnaires completed were filled out by patients and their sleep partners separately. Nevertheless, the high response rate shows that the role played by the family circle is an important issue for the Home Care Provider and the specialist with respect to disease management. It is also likely that the most dedicated sleep partners and the patients the most at ease with the treatment are those who responded. However it is clear, upon analysis of the responses, that their potential role can be improved.

\section{CONCLUSION}

SLEEP APNOEA SYNDROME and CPAP treatment have a notable impact on sleep partners. Even if the disease has a negative impact on the couple in general, the benefits of CPAP treatment are felt by both patients and their family circle; treating the patient often means treating the sleep partner at the same time. According to our observations, sleep partners not only play an essential role in detecting and diagnosing the disease but also influence CPAP use and continuation of treatment. The involvement of family members at the time of diagnosis and in disease monitoring appears to be essential. They have specific expectations which should be taken into account by doctors and Home Care providers. Providing additional information and therapeutic education is the key to effectively managing patients suffering from SLEEP APNOEA SYNDROME. Analyzing the reasons for non-compliance with treatment/removal of fitted devices and the role played by the partner may also be very useful in practice and could form the subject of an additional study. Global disease management for patients should include their family and next of kin who have a strong influence on their psychological well-being, their way of dealing with the disease and their attitude to treatment. Finally, specialists' perception of the contribution made by the SLEEP APNOEA SYNDROME sufferer's family circle is also a route that remains to be explored.

\section{SUPPORT/INTEREST}

Orkyn' is a French Home care provider. It supplies CPAP for patients presenting with sleep apnea. "Association Passerelles éducatives" is a leading association in respiratory patient education.

\section{REFERENCES}

[1] Redline S, Strohl KP. Recognition and consequences of obstructive sleep apnea hypopnea syndrome. Clin Chest Med 1998; 19: 1-19J.

[2] Young T, Palta M, Dempsey J, et al. The occurrence of sleepdisordered breathing among middle-aged adults. N Engl J Med 1993; 328: 1230-5.

[3] Jennings JR, Muldoon MF, Hall M, Buysse DJ, Manuck SB. Selfreported sleep quality is associated with the metabolic syndrome. Sleep 2007; 30(2): 219-23.

[4] Vgontzas AN, Bixler EO, Chrousos GP. Sleep apnea is a manifestation of the metabolic syndrome. Sleep Med Rev 2005; 9(3): 211 24.

[5] Flemons WW, Tsai W. Quality of life consequences of sleepdisordered breathing. J Allergy Clin Immunol 1997; 99: S750-S6.

[6] Ashtyani H. Hutter D.A. Collateral damage: The effects of obstructive sleep apnea on bed partners. Chest 2003; 124: 780-1.

[7] Parish J-M, Lyng P-J. Quality of life in bed partners of patients with obstructive sleep apnea or hypopnea after treatment with continuous positive airway pressure. Chest 2003 ; 124: 942-7.

[8] Beninati W, Harris CD, Herold DL, et al. The effect of snoring and obstructive sleep apnea on the sleep quality of bed partners. Mayo Clin Proc 1999; 74: 955-8.

[9] Breugelmans G, Ford D-E, Smith P-L, Punjabi N-M. Differences in patient and bed partner-assessed quality of life in sleep-disordered breathing. Am J Respir Crit Care Med 2004; Vol. 170: pp. 547552 .

[10] McArdle N, Kingshott R, Engleman HM, Mackay TW, Douglas NJ. Partners of patients with sleep apnoea/hypopnoea syndrome: effect of CPAP treatment on sleep quality and quality of life. Thorax 2001; 56(7): 513-8.

[11] Kiely JL, McNicholas WT. Bed partners' assessment of nasal continuous positive airway pressure therapy in obstructive sleep apnea. Chest 1997; 111: 1261-5.

(C) Ellenberg et al.; Licensee Bentham Open.

This is an open access article licensed under the terms of the Creative Commons Attribution Non-Commercial License (http://creativecommons.org/licenses/by-nc/3.0/) which permits unrestricted, non-commercial use, distribution and reproduction in any medium, provided the work is properly cited. 